\title{
The citrus flavanone naringenin suppresses CYP1B1 transactivation through antagonising xenobiotic-responsive element binding
}

\author{
Ching Ho Poon ${ }^{1}$, Tsz Yan Wong ${ }^{2}$, Yanfei Wang ${ }^{3}$, Yuki Tsuchiya ${ }^{4}$, Miki Nakajima ${ }^{4}$, Tsuyoshi Yokoi ${ }^{4}$ and \\ Lai K. Leung $2,3 *$ \\ ${ }^{1}$ Molecular Biotechnology Programme, School of Life Sciences, Faculty of Science, The Chinese University of Hong Kong, \\ Shatin, N.T., Hong Kong \\ ${ }^{2}$ Food and Nutritional Sciences Programme, School of Life Sciences, The Chinese University of Hong Kong, Room 507C MMW \\ Building, Shatin, N.T., Hong Kong \\ ${ }^{3}$ Biochemistry Programme, School of Life Sciences, Faculty of Science, The Chinese University of Hong Kong, Shatin, N.T., \\ Hong Kong \\ ${ }^{4}$ Division of Drug Metabolism, Faculty of Pharmaceutical Sciences, Kanazawa University, 13-1 Takara-machi, Kanazawa \\ 920-0934, Japan
}

(Submitted 26 March 2012 - Final revision received 13 July 2012 - Accepted 13 July 2012 - First published online 31 August 2012)

\begin{abstract}
Exposure to environmental toxicants or exogenous oestrogen increases the risk of cancer. Some toxicants such as polycyclic aromatic hydrocarbons (PAH) undergo biotransformation to become genotoxic agents. Cytochrome p450 (CYP) 1B1 is an enzyme catalysing this transformation. Consumption of fruit and vegetables is considered to be protective against carcinogenesis, and naringenin can be found abundantly in citrus fruits. In the present study, the effect of naringenin on the regulation of CYP1B1 was investigated in MCF-7 cells. Enzyme inhibition assays revealed that naringenin inhibited CYP1B1 at or above $5 \mu \mathrm{m}$ but not CYP1A1 activity. Quantitative PCR analysis also demonstrated that $1 \mu \mathrm{m}$-naringenin reduced CYP1B1 mRNA expression induced by 7,12-dimethylbenz( $\alpha$ )anthracene (DMBA). Further study illustrated that the suppression was at the transcriptional level. Since previous studies have shown that oestrogen response element (ERE) and xenobiotic-responsive element (XRE) are functional binding sequences in the promoter region of $C Y P 1 B 1$, interference of DNA binding on these two elements was pursued. Employing reporter gene assays as well as the electromobility shift assay, we verified that naringenin counteracted DMBA-induced XRE binding at -1675 . These results supported the notion that fruit consumption could be a protective measure against PAH biotransformation.
\end{abstract}

Key words: Citrus flavonoids: Naringenin: CYP1B1

Citrus fruits contain an ample amount of vitamin $\mathrm{C}$ and are an important food group in our diet. In addition to this essential nutrient, they also contain phytochemicals that may improve our health. Naringenin is the major bioflavonoid isolated from citrus fruits. Animal studies have demonstrated that the administration of naringenin can deter or protect against 7,12-dimethylbenz $(\alpha)$ anthracene (DMBA)-induced mammary tumorigenesis ${ }^{(1)}$, azoxymethane-induced colon carcinogenesis $^{(2)}$, DMBA-induced oral carcinogenesis ${ }^{(3)}$ and $N$-methyl$N$-nitro- $N$-nitroso-guanidine-induced gastric carcinogenesis ${ }^{(4)}$.

Polycyclic aromatic hydrocarbons (PAH) are chemical carcinogens that can be found in industrial emissions, char-broiled meat, tobacco smoke and overheated cooking oil ${ }^{(5,6)}$. Upon exposure, our body metabolises these compounds into
DNA-attacking species through cytochrome p450 (CYP) 1A1 and $1 \mathrm{~B} 1$ catalysis $^{(7)}$. On the other hand, PAH are ligands to the aryl hydrocarbon receptor (AhR). After binding to $\mathrm{PAH}$, the AhR migrates to the nucleus and dimerises with the AhR nuclear translocator. The dimer interacts with xenobioticresponsive element (XRE) and stimulates the transcription of genes coding for CYP1 family enzymes ${ }^{(8-10)}$. The observations that PAH fails to induce tumours in $\mathrm{AhR}^{(11)}$ or $\mathrm{CYP} 1 \mathrm{~B} 1^{(12)}$ knockout mice illustrate the importance of the respective proteins in the process of carcinogenesis.

The significance of CYP1B1 in human carcinogenesis is still unclear. $C Y P 1 B 1$ polymorphisms with increased activity are associated with breast cancer risk in Asian women ${ }^{(13)}$. Increased CYP1B1 activity or expression can also be affected

Abbreviations: AhR, aryl hydrocarbon receptor; CYP, cytochrome p450; DMBA, 7,12-dimethylbenz( $\alpha$ )anthracene; ERE, oestrogen response element; EROD, ethoxyresorufin-O-deethylase; PAH, polycyclic aromatic hydrocarbons; XRE, xenobiotic-responsive element.

*Corresponding author: L. K. Leung, fax +852 26037732, email laikleung@cuhk.edu.hk 
by other gene expression. Polymorphism of $A b R$ resulting in lower mRNA expression may also lower the mRNA expressions of $A R N T$ and $C Y P 1 B 1^{(14)}$. However, metaanalyses on the association of CYP1B1 and breast cancer risk display mixed results ${ }^{(15,16)}$.

Many PAH have been isolated in the diet ${ }^{(17)}$, and DMBA is a model PAH commonly used in experiments. The effect of DMBA on gene expression should parallel those of dietary $\mathrm{PAH}$. The present study was designed to examine the inhibitory effect of naringenin on CYP1B1 expression and enzyme activity. As aforementioned that CYP1B1 is an important enzyme in PAH-induced carcinogenesis, the present study might elucidate the underlying mechanism of the chemoprevention of diets rich in fruit and vegetables. In the promoter region of $C Y P 1 B 1$, researchers have located eight XRE and one oestrogen response element (ERE) with verified functionalities $^{(18,19)}$. Since naringenin is a weak agonist to the oestrogen receptor ${ }^{(20)}$ and $\mathrm{AhR}^{(21)}$, we hypothesised that the citrus flavonoid suppresses CYP1B1 expression through antagonising ERE or XRE DNA binding. Concentrations of naringenin covering the physiological as well as pharmacological intake were administered.

\section{Materials and methods \\ Chemicals}

Naringenin, ethoxyresorufin and DMBA were purchased from Sigma Chemicals. All other chemicals, if not stated, were acquired from Sigma Chemicals.

\section{Cell culture}

MCF-7 cells (American Type Culture Collection) were cultured in Roswell Park Memorial Institute-1640 phenol red-free media (Sigma Chemicals) with 10\% fetal bovine serum (Invitrogen Life Technology) and incubated at $37^{\circ} \mathrm{C}$ and $5 \% \mathrm{CO}_{2}$. These cells were routinely subcultured when reaching $80 \%$ of confluency. Cell density in each experiment was maintained at $5 \times 10^{2}$ cells $/ \mathrm{mm}^{2}$.

\section{Ethoxyresorufin-O-deethylase activities in intact MCF-7 cells}

The ethoxyresorufin-O-deethylase (EROD) activity assay method was performed as described previously ${ }^{(22)}$. In brief, MCF-7 cells in ninety-six-well plates were treated with $1 \mu \mathrm{M}$ DMBA and $0 \cdot 1,1$ or $5 \mu \mathrm{m}$-naringenin. The medium was then removed and the cells were washed twice by $100 \mu \mathrm{l}$ PBS. Then, $50 \mu \mathrm{l}$ ethoxyresorufin $(5 \mu \mathrm{M})$ and salicyclamide $(1.5 \mathrm{~mm})$ dissolved in PBS were added in each well, and incubated at $37^{\circ} \mathrm{C}$ for $15 \mathrm{~min}$. The reaction was stopped by $50 \mu \mathrm{l}$ of ice-cold methanol, and the resorufin generated was measured by a FLUOstar Galaxy microplate reader (BMG Labtechnologies) with an excitation wavelength at 544 and $590 \mathrm{~nm}$ as the emission wavelength. The activities were quantified against resorufin standards.

\section{Enzyme inhibition assays}

Recombinant human CYP1A1 and CYP1B1 proteins expressed in insect cells (Supersomes ${ }^{\circledR}$ ) were purchased from Gentest Corporation. In brief, $2 \mathrm{pmol}$ of protein were incubated in $100 \mu \mathrm{l}$ PBS, pH 7.2 with 400 nm-ethoxyresorufin and naringenin in different concentrations. The reaction was initiated by adding $500 \mu \mathrm{M}-\mathrm{NADPH}$, and terminated by adding $100 \mu \mathrm{l}$ of ice-cold methanol after $20 \mathrm{~min}$ of incubation. Fluorescence was measured as described earlier.

\section{Quantitative real-time RT-PCR assay}

MCF-7 cells were seeded in six-well Costar plates and underwent various treatments. After $24 \mathrm{~h}$, total RNA was extracted from the cells using TRIzol reagent (Invitrogen). The RNA's concentration and purity were determined by its absorbance at $260 / 280 \mathrm{~nm}$. First DNA strands were synthesised from $3 \mu \mathrm{g}$ of total RNA using oligo-dT primers and Moloney murine leukaemia virus reverse transcriptase (USB Corporation). Target fragments were quantified by real-time PCR and an ABI Prism 7700 Sequence Detection System (Applied Biosystems) was employed for these assays. Taqman ${ }^{\circledR} / \mathrm{VIC}^{\circledR}$ MGB probes and primers for CYP1B1 and GAPDH (Assay-on-Demand ${ }^{\mathrm{TM}}$ ) and Real-time PCR Taqman Universal PCR Master Mix were all obtained from Applied Biosystems. PCR were set up as described in the manual, which were validated by the company. Signals obtained for glyceraldehyde-3-phosphate dehydrogenase served as a reference to normalise the amount of RNA amplified in each reaction. Relative gene expression was analysed using the $2^{\Delta \Delta \mathrm{Ct}} \operatorname{method}^{(23)}$.

\section{Western blot analysis}

Cells were washed once with PBS ( $\mathrm{pH} 7 \cdot 4)$ and harvested into a $1.5 \mathrm{ml}$ microtube with $0.5 \mathrm{ml}$ lysis buffer (PBS, $1 \% \mathrm{NP} 40,0.5 \%$

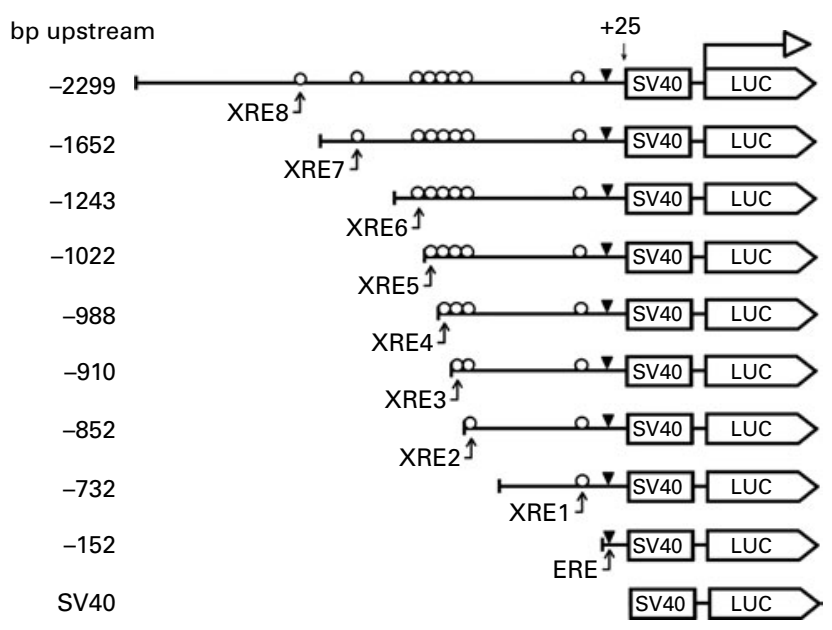

Fig. 1. Design of the CYP1B1 truncation reporter gene plasmids. Xenobioticresponsive elements (XRE) within the CYP1B1 promoter were sequentially truncated. Locations of the response elements are oestrogen response element (ERE) ( -63 to -49$)$, XRE1 ( -268 to -264$)$, XRE2 ( -838 to -834 ), XRE3 ( -853 to -849$)$, XRE4 ( -944 to -940$)$, XRE5 ( -993 to -989$)$, XRE6 ( -1028 to -1024$)$, XRE7 ( -1494 to -1490$)$ and XRE8 $(-1679$ to -1675$)$ The design facilitated the identification of a specific XRE interaction. SV40, Simian Virus 40 sequence; LUC, firefly luciferase sequence. 


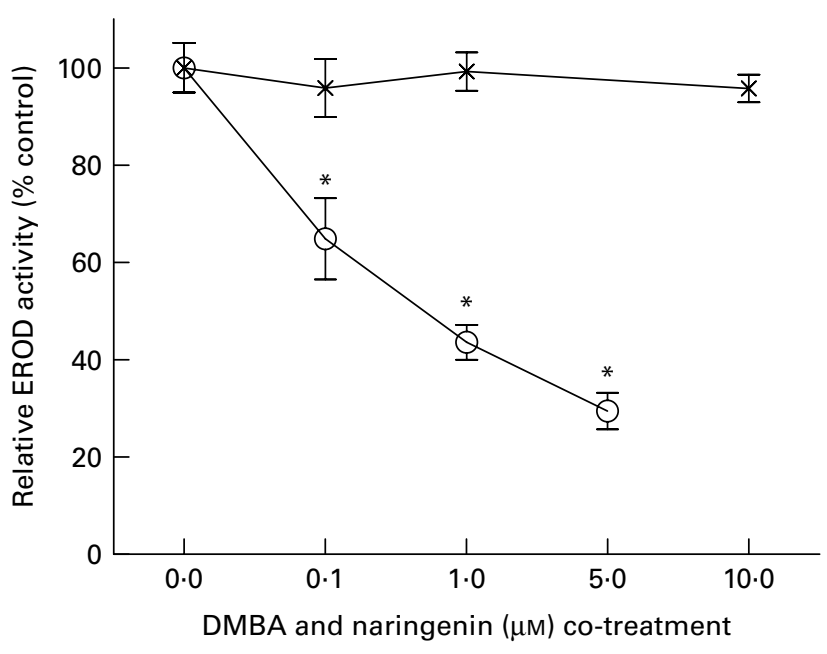

Fig. 2. Naringenin $(*)$ inhibited ethoxyresorufin-O-deethylase (EROD) activity in 7,12-dimethylbenz $(\alpha)$ anthracene (DMBA)-induced MCF-7 cells. MCF-7 cells were seeded in ninety-six-well culture plates and treated with naringenin or $\mathrm{co}-$ treated with $1 \mu \mathrm{M}-\mathrm{DMBA}$ and naringenin (- - ). After $24 \mathrm{~h}$ of treatment, the cells were assayed for EROD activity, and cell viability was determined on a separate set of cultures with equivalent treatment. Values are means $(n 4)$, with their standard errors represented by vertical bars. * Mean values were significantly lower than the cultures treated with DMBA alone $(P<0.05)$.

sodium deoxycholate and $0 \cdot 1 \%$ SDS). The lysis buffer contained protease inhibitors ( $40 \mathrm{mg}$ phenylmethylsulfonyl fluoride $/ 1,0.5 \mathrm{mg}$ aprotinin $/ 1,0.5 \mathrm{mg}$ leupeptin/1, 1.1 mm-EDTA and $0.7 \mathrm{mg}$ pepstatin/l) and phosphatase inhibitor cocktail (PhosphoSTOP tablet; Roche). The harvested cells were then lysed with a cell disruptor (Branson Ultrasonics Corporation) on ice for $30 \mathrm{~s}$. The protein concentration of cell lysate was determined by DC protein assay (BioRad). Then, $50 \mu \mathrm{g}$ of lysate protein were separated on $10 \%$ SDS-PAGE and transferred onto an Immobilon PVDF membrane (Millipore). Anti-CYP1B1 (Abcam) and anti-actin primary (Sigma Chemicals) and secondary antibodies conjugated with horseradish peroxidase (Santa Cruz Biotechnology) were used for protein detection. An Enhanced Chemiluminescence Detection Kit (Amersham) provided the chemiluminescence substrate for HRP, and the targeted protein was visualised by autoradiography.

\section{Luciferase reporter gene assay}

Construction of the CYP1B1 truncation reporter gene plasmid. The 5'-flanking region upstream $(-2299$ to +25$)$ from human CYP1B1 was cloned in the pGL3-promoter plasmid. Different truncation plasmids were constructed from the region as listed in Fig. 1. The detailed procedure has been described previously ${ }^{(18)}$.

Construction of xenobiotic-responsive element-driven reporter gene plasmids. XRE-driven reporter plasmids were constructed as described previously ${ }^{(24)}$. The synthesised XREcontaining fragment was digested with SmaI and Bam HI and subcloned into a firefly luciferase reporter vector pTA-Luc (Clontech). ERE-luciferase reporter plasmids were gifts from Dr D McDonnell (Duke University, NC, USA). These two plasmids were known to be responsive to XRE or ERE activation only.

Dual luciferase assays. MCF-7 cells were seeded at $10^{5}$ cells/well in twenty-four-well plates. After $24 \mathrm{~h}$, transient trans- fection was performed using $1 \mu$ l Lipofectamine and $2 \mu$ l Plus reagent (Invitrogen Life Technologies) per well. Reporter plasmids $(0.25 \mu \mathrm{g}$, containing DNA fragments derived from the CYP1B1 promoter or XRE) were transfected into cells in serum-free medium. The renilla luciferase vector pRL-CMV (Promega Corporation) was co-transfected as an internal correction for transfection efficiency. After $6 \mathrm{~h}$ incubation, cells were cultured in phenol red-free medium supplemented with $10 \%$ charcoal dextran-treated FBS. The medium was removed $16 \mathrm{~h}$ later and the cells were treated with $1 \mu \mathrm{M}$-DMBA and $0 \cdot 1,1$ or $10 \mu \mathrm{M}$-naringenin for $24 \mathrm{~h}$. The cells were lysed, and the activities of the luciferases were determined using the Dual-Luciferase Assay Kit (Promega Corporation). Luciferase bioluminescence was quantified by using a FLUOstar Galaxy plate reader. Transactivation activities represented by firefly luciferase light units were then normalised with that of renilla luciferase.

\section{Electrophoretic mobility shift assay}

Nuclear protein extract was isolated by using the NucBuster ${ }^{\mathrm{TM}}$ protein extraction kit (Novagen ${ }^{\circledR}$; EMD Biosciences, Inc.). In brief, cells were co-treated with DMBA and naringenin. After $24 \mathrm{~h}$ of incubation, the cells were washed, trypsinised and centrifuged at $500 \mathrm{~g}$ at $4^{\circ} \mathrm{C}$. Reagent 1 was added to the packed cells. Nuclear extract was isolated from the cell suspension by vortexing and centrifugation. The nuclear protein was stored at $-80^{\circ} \mathrm{C}$ until assayed. XRE oligonucleotide, as designed below, was synthesised and labelled by the DIG Gel Shift Kit, $2^{\text {nd }}$ Generation (Roche Diagnostics GmbH):

\section{5’ - AGCGTGTGCGTGAGCGTGTGCGTGAGCGTGTGCGT}

\section{GAGCGTGTGCGTG $-3^{\prime}$.}

The nuclear protein was incubated with the labelled probe, sonicated salmon sperm DNA, poly(deoxyinosinic-deoxycytidylic) and binding buffer ( $400 \mathrm{~mm}-\mathrm{KCl}, 80 \mathrm{~mm}$-HEPES, 2 mm-dithiothreitol, $0.8 \mathrm{~mm}$-EDTA and $80 \%$ glycerol, $\mathrm{pH} 8$ )

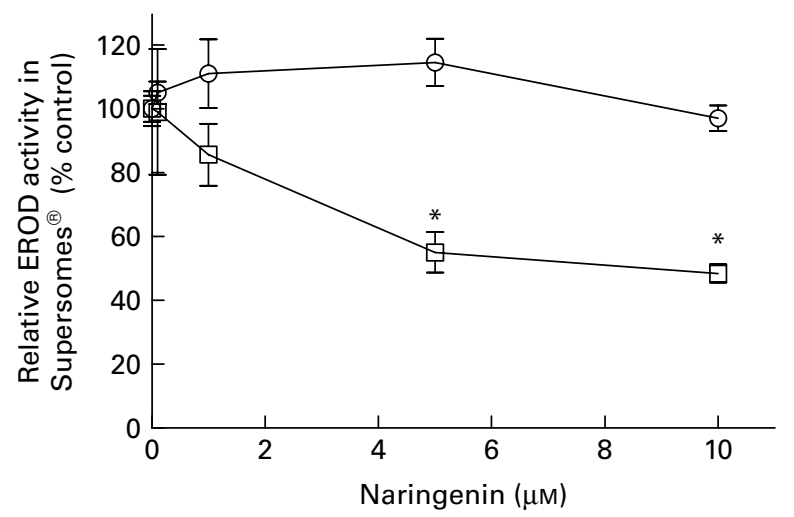

Fig. 3. Enzyme inhibition assay of naringenin on recombinant CYP1A1 and CYP1B1 proteins. Ethoxyresorufin-O-deethylase (EROD) assay was performed on human recombinant CYP1A1 ( $\odot$ ) and CYP1B1 ( $\square)$ in the presence of the indicated concentrations of naringenin and ethoxyresorufin. Values are means ( $n 3$ ), with their standard errors represented by vertical bars. *Mean values were significantly lower than samples treated with 7,12-dimethylbenz $(\alpha)$ anthracene alone $(P<0.05)$. 
provided in an electrophoretic mobility shift assay accessory kit (Novagen) for $30 \mathrm{~min}$ at room temperature. The reaction mix was then separated on a $4-6 \%$ non-denaturing gel in $0.5 \times$ Tris-borate-EDTA at $100 \mathrm{~V}$. The labelled oligonucleotide was electrotransferred to a Nylon membrane, fixed by UV light, blocked and washed. The shifted oligonucleotide was detected by the anti-Digoxigenin-AP conjugate and the chemiluminescent substrate $\operatorname{CSPD}^{\circledR}$ provided in the kit.

\section{Statistical methods}

A Prism ${ }^{\circledR} 5.0$ (GraphPad Software, Inc.) software package was used for statistical analysis. Results were analysed by one-way ANOVA followed by the post boc ranking test and the significant level was set at $P<0 \cdot 05$.

\section{Results}

\section{Effect of naringenin on ethoxyresorufin-O-deethylase} activity in MCF-7 cells

EROD activity was determined in intact MCF-7 cells treated with DMBA and naringenin. The results indicated that

(A)

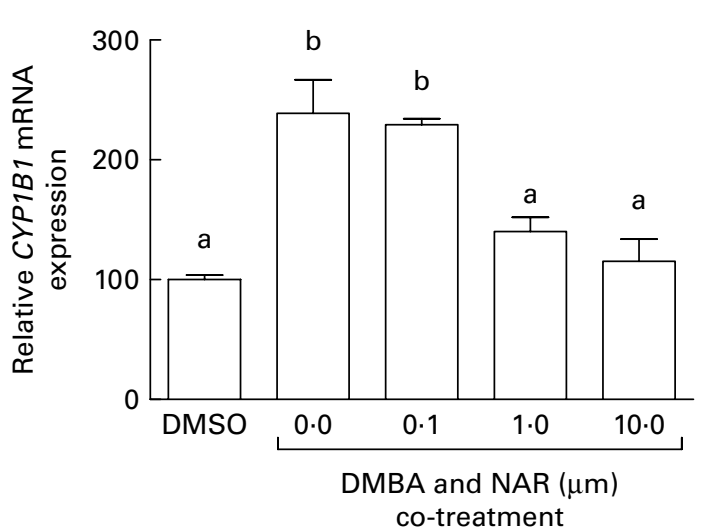

naringenin was able to impede DMBA-induced EROD activity at or above $0 \cdot 1 \mu \mathrm{M}$ (Fig. 2). The $\mathrm{IC}_{50}$ value was estimated to be about $0.5 \mu \mathrm{m}$-naringenin. EROD activity presented was normalised by absorbance obtained from the 3-(4,5dimethylthiazol-2-yl)-2,5-dipheryltetrozolium bromide (MTT) assay.

\section{Analysis on the inhibition of CYP1 enzymes}

EROD activity was decreased in cultures co-treated with naringenin, and the results could be contributed by CYP1A1 and CYP1B1 inhibition. Therefore, specific enzyme inhibition assays were carried out on recombinant human CYP1A1 and CYP1B1 enzymes. The results showed that naringenin inhibited CYP1B1 but not CYP1A1 in the concentration range tested (Fig. 3), and the $\mathrm{IC}_{50}$ value was about $5 \mu \mathrm{m}$.

\section{CYP1B1 mRNA expression}

Real-time RT-PCR showed that the DMBA treatment significantly $(P<0.05)$ increased the levels of $C Y P 1 B 1$ mRNA by $2 \cdot 5$-fold. The induced expression of $C Y P 1 B 1 \mathrm{mRNA}$ was significantly $(P<0.05)$ reduced by naringenin at concentrations

(C)

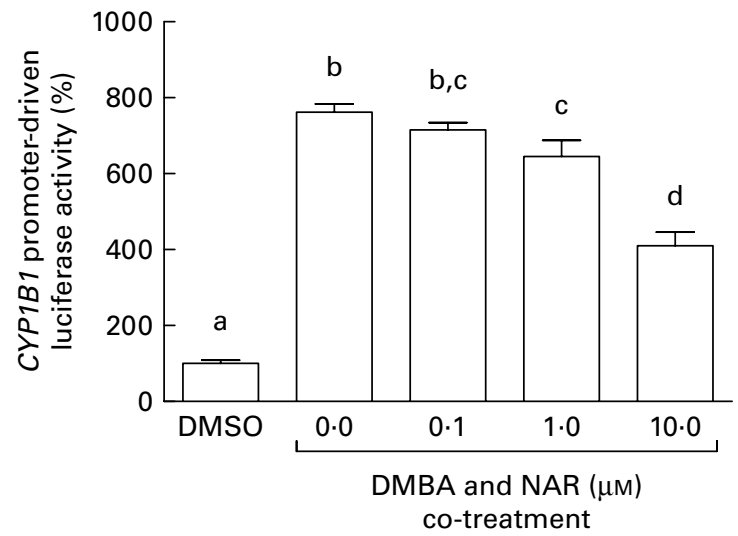

(B)

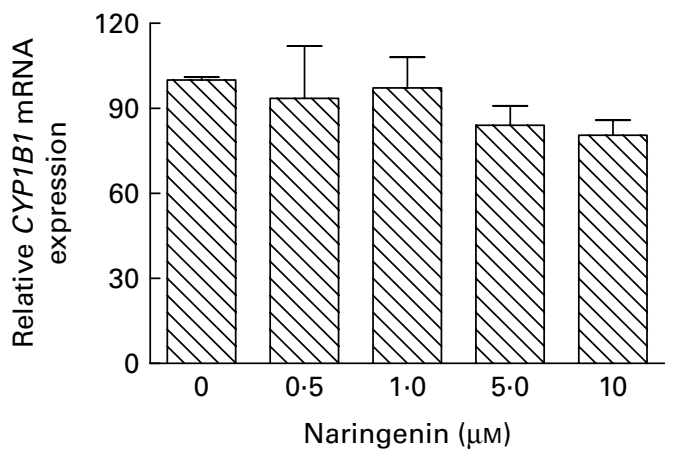

(D)

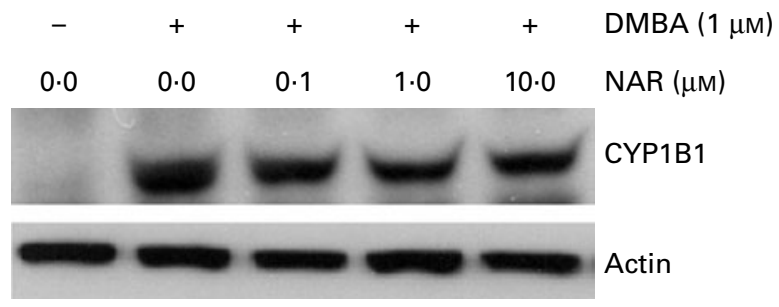

Fig. 4. Effect of naringenin (NAR) on CYP1B1 expression. MCF-7 cells were (A) co-treated with $1 \mu M-7,12$-dimethylbenz $(\alpha)$ anthracene (DMBA) and NAR or (B) treated with NAR alone, and cultured for $24 \mathrm{~h}$. mRNA expression of CYP1B1 was quantified by real-time RT-PCR. Values are means ( $n$ 3), with their standard errors represented by vertical bars. Mean values were significantly different $(P<0.05)$ among the treatments and the order is $b>a$. (C) Reporter gene assay was performed to verify the transcriptional regulation. In this assay, MCF-7 cells were seeded in twenty-four-well plates and were transfected with CYP1B1 reporter plasmid (-2299) and treated with NAR. Luciferase activities were determined in the cell lysate. Values are means $(n 3)$, with their standard errors represented by vertical bars. Mean values with unlike letters were significantly different $(P<0.05)$, and the order is $b>c>d>a$. (D) The immunoblot image of the CYP1B1 protein, which is a representation of two independent experiments with similar results. DMSO, dimethyl sulfoxide. 
(A)

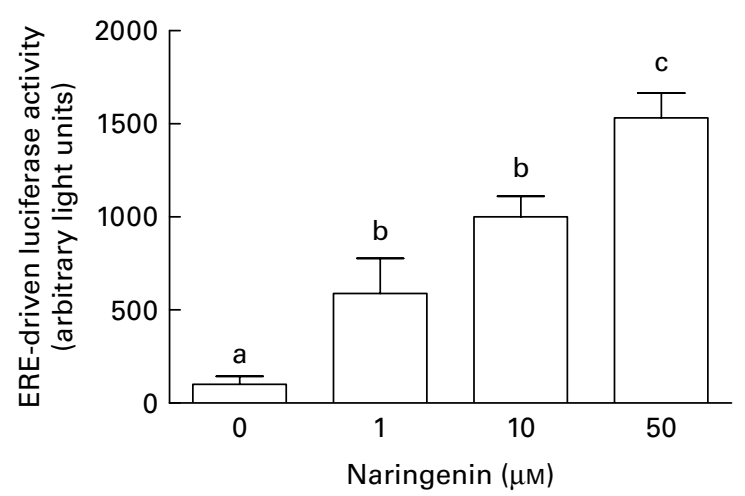

(B)

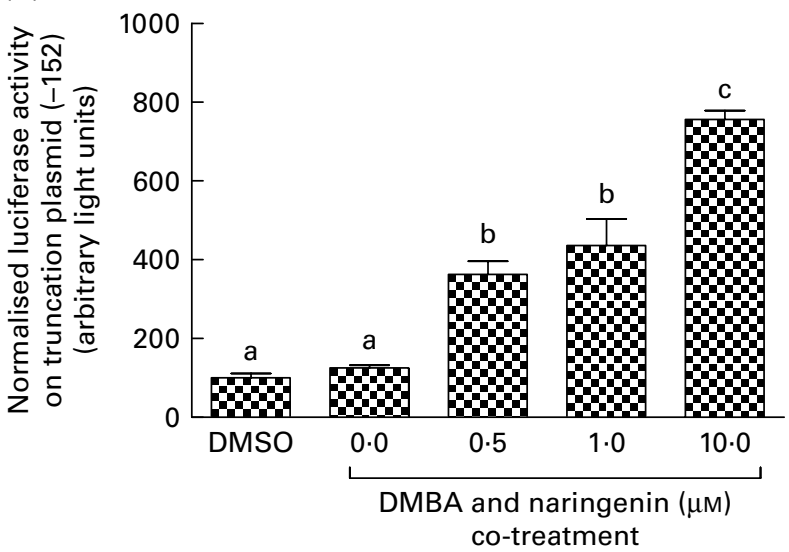

Fig. 5. Naringenin activated oestrogen response element (ERE). MCF-7 cells were seeded in forty-eight-well plates and maintained in Roswell Park Memorial Institute-1640 medium. The cells were switched to serum-free medium for $6 \mathrm{~h}$ and transfected with (A) ERE-driven reporter gene plasmid or (B) CYP1B1 $(-152)$ truncation reporter plasmid. The cells were then treated with naringenin and assayed for luciferase activities. Values are means $(n 3)$, with their standard errors represented by vertical bars. Mean values with unlike letters were significantly different $(P<0.05)$, and the order is b $>c>a$. DMSO, dimethyl sulfoxide.

ranging from 1 to $10 \mu \mathrm{M}$ (Fig. 4(A)). However, naringenin given alone had no effect on the expression (Fig. 4(B)). The results indicated that naringenin by itself has no effect on CYP1B1 transcription.

\section{Reporter gene assay on CYP1B1 promoter}

As the DMBA-induced CYP1B1 mRNA expression was suppressed by naringenin, CYP1B1 promoter-driven luciferase reporter assay was performed to verify whether the gene transactivation was repressed by naringenin. The results demonstrated that naringenin suppressed the promoter transactivation at or above $1 \mu \mathrm{M}$ (Fig. 4(C)) and was consistent with the mRNA results.

\section{Immunoblot of CYP1B1}

The Western blot results (Fig. 4(D)) were similar to the trend of mRNA. The results implicated that the expression of CYP1B1 under the naringenin treatment was probably regulated at the transcriptional level.

\section{Oestrogen response element-driven luciferase activities}

These reporter assays were carried out because ERE and XRE motifs have been located in the promoter region of $C Y P 1 B 1$. Naringenin by itself could induce ERE-driven luciferase activity (Fig. 5(A)) and the activity of the truncation reporter plasmid (-152) was induced in the co-treatment with DMBA (Fig. 5(B)). As plasmid (-152) contained an ERE, these data did not support the hypothesis that naringenin suppressed CYP1B1 mRNA expression by antagonising oestrogen receptor binding.
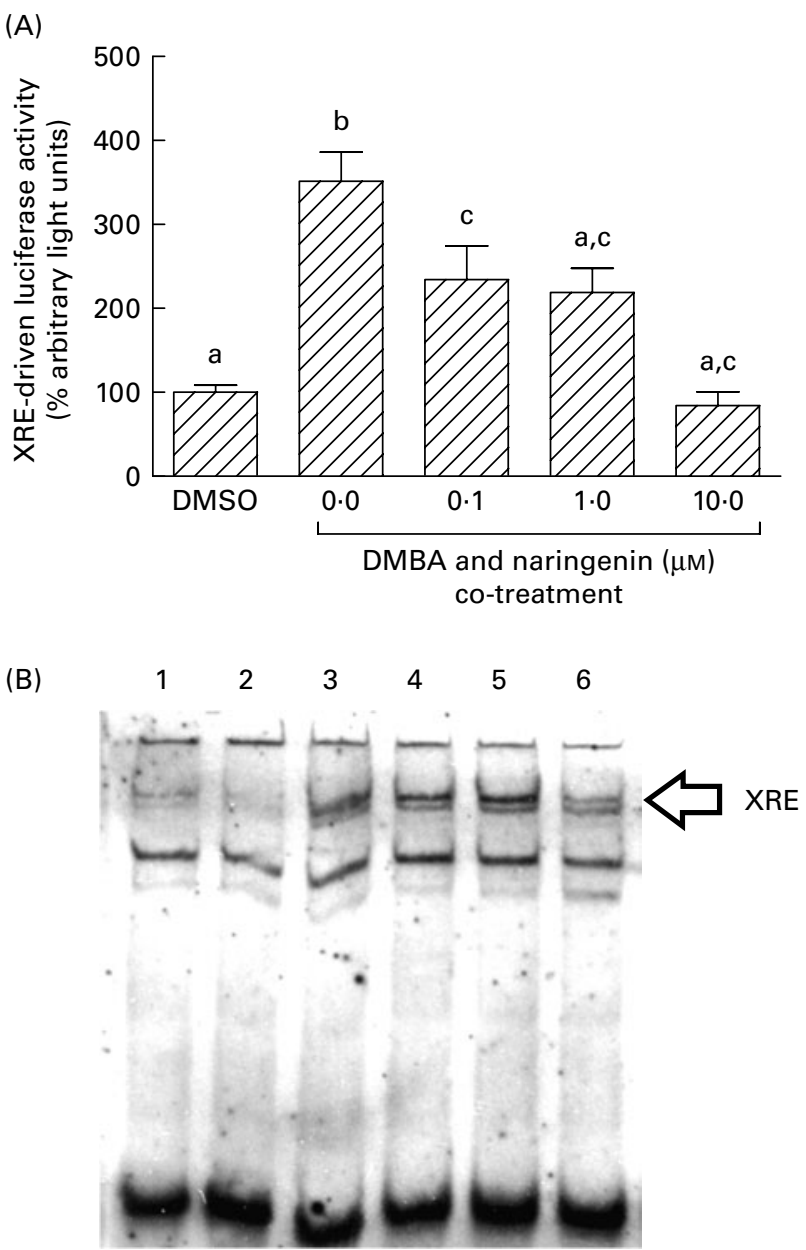

Fig. 6. Gene transactivation with respect to xenobiotic-responsive element (XRE). MCF-7 cells were seeded in forty-eight-well plates and maintained in Roswell Park Memorial Institute-1640 medium. The cells were switched to serum-free medium for $6 \mathrm{~h}$ and transfected with XRE-driven reporter gene plasmids. (A) The cells were then treated with naringenin and assayed for luciferase activities. Values are means $(n 3)$, with their standard errors represented by vertical bars. Mean values with unlike letters were significantly different $(P<0.05)$, and the order is $\mathrm{b}>\mathrm{c}>\mathrm{a}$. Subsequently, nuclear extract samples were prepared from the 7,12-dimethylbenz $(\alpha)$ anthracene (DMBA) and naringenin co-treated MCF-7 cells and electrophoretic mobility shift assay was performed. (B) Lanes labelled with 3-6 are samples incubated with the respective naringenin concentrations of $0,0.1,1.0$ and $10.0 \mu \mathrm{M}$ under DMBA co-treatment; lane 1 is the sample extracted from DMBA treatment and incubated with Ah receptor antibody; lane 2 is the sample treated with the carrier solvent dimethyl sulfoxide (DMSO) only. Data represent one of two independent experiments with comparable results. 
Xenobiotic-responsive element-driven luciferase activities

On the other hand, DMBA induced the XRE-driven luciferase activity by about $3 \cdot 5$-fold, and this induction was significantly repressed by co-treating with naringenin at concentrations as low as $0 \cdot 1 \mu \mathrm{m}$ (Fig. 6(A)). Further study by using the electrophoretic mobility shift assay indicated a similar trend in the
DMBA-induced XRE binding and the repression by naringenin (Fig. 6(B)).

\section{Reporter gene assay on truncated CYP1B1 promoter}

In order to identify the specific XRE was antagonised by naringenin, a series of truncation reporter plasmids were con-

$-1226$

$-2299$

$\triangle \backslash-1652$

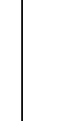

DMBA+NAR $(10 \mu \mathrm{M})$

DMSO

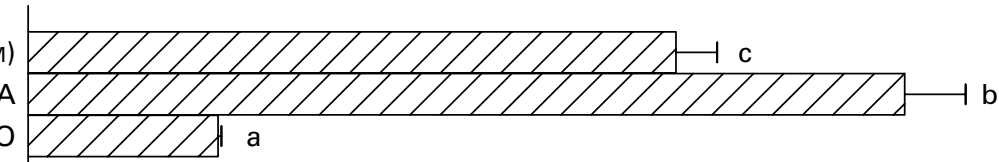

$\rightleftarrows$

$-1022$

AIIV

$-988$

$$
\mp
$$

DMBA+NAR (10

DMSO

$(10 \mu \mathrm{m})$

DMBA

DMSO

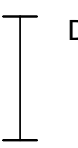

DMBA+NAR $(10 \mu \mathrm{M})$

DMBA

DMSO

DMBA+NAR $(10 \mu \mathrm{M})$
DMBA
DMSO

DMBA+NAR $(10 \mu \mathrm{m})$
DMBA
DMSO

VIIIS -910

$\square \square-852$

$\perp$

DMBA+NAR $(10 \mu \mathrm{M})$

DMBA

DMSO

$\perp$

$-732$

DMBA+NAR $(10 \mu \mathrm{M})$

DMBA

DMSO

$\perp$

표묘

$-152$

DMBA+NAR (10 $\mu \mathrm{M})$

DMBA

DMSO

DMBA+NAR $(10 \mu \mathrm{M}) \quad \because \cdots$

DMBA $\because$ H

DMSO

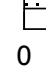

Normalised luciferase activity (arbitrary light units)

Fig. 7. Identification of the xenobiotic-responsive element-specific transactivation domain by using the truncation reporter gene assay. MCF-7 cells were seeded in forty-eight-well plates and maintained in Roswell Park Memorial Institute-1640 medium. The cells were switched to serum-free medium for $6 \mathrm{~h}$ and transfected with a series of CYP1B1 truncation reporter plasmids. The cells were then treated with $10 \mu \mathrm{M}$-naringenin (NAR) and assayed for luciferase activities. Values are means $(n 3)$, with their standard errors represented by horizontal bars. Mean values with unlike letters were significantly different $(P<0.05)$ under the same truncation plasmid, and the order is $b>c>a$. DMBA, 7,12-dimethylbenz[ $\alpha$ ]anthracene; DMSO, dimethyl sulfoxide; SV40, Simian virus 40. 
structed. Among all reporter signals from the XRE-containing truncation plasmids, only those from plasmids (-988) and $(-2299)$ were significantly induced by DMBA (Fig. 7). However, naringenin appeared to be only counteracting $\mathrm{XRE}^{(8)}$ in plasmid (-2299). Naringenin co-administered with DMBA induced luciferase activity in plasmid $(-152)$, but the induction was not caused by DMBA. As demonstrated in Fig. 5, naringenin should be responsible for the induction through ERE binding. However, the induction was not carried over beyond $(-152)$. Some silencing factors could be present from -152 to -910 and from -988 to -1652 since luciferase activity progressively decreased in this 5 -flanking region.

\section{Discussion}

Similar to previous findings ${ }^{(25)}$, naringenin inhibited recombinant CYP1B1 but not CYP1A1 in the present investigation. As the inhibition on cellular EROD activity was more potent than that in the recombinant protein, we also evaluated the phytochemical's effect on the transcriptional control of CYP1B1. The present results demonstrated that naringenin suppressed DMBA-induced CYP1B1 mRNA expression by antagonising XRE binding. Although the CYP1B1 promoter segment encompassing ERE was activated by naringenin, the response element did not take part in the gene transactivation. On the other hand, naringenin was not demonstrated to be a ligand of AhR in the present study. It could interact with the AhR at a non-ligand binding region and induced conformational changes in the ligand-binding domain or the ARNT-interacting domain. The altered structure of AhR prevented the receptor from binding to PAH or ARNT. A previous study has shown that inhibitors of heat shock protein $90^{(26)}$ may deter CYP1B1 transcription. Alternatively, the flavonoid could inhibit heat shock protein 90 and prevented the nuclear translocation of AhR.

CYP1B1 contains eight XRE in its promoter region. The position of specific XRE activation and/or suppression could be important in regulating CYP1B1 transactivation. A previous study has shown that XRE interactions at -834 and -853 are essential for the transcriptional control under 2,3,7,8-tetrachlorodibenzo-p-dioxin treatment ${ }^{(18)}$. By contrast, XRE transactivations at -940 and -1675 were induced by DMBA in the present study. However, only the latter XRE appeared to be suppressed by naringenin. Another possible interacting sequence was ERE. Since naringenin is a weak agonist to the oestrogen receptor and a functional ERE site is located in the 5'-flanking region of CYP1B1, the phytochemical could exert agonist/antagonist activity to the oestrogen receptor and block the transcriptional activity. However, the present data suggested that the interaction at ERE $(-152)$ was augmented rather than suppressed in cells co-treated with DMBA and naringenin. The induction signal was silenced as the length of the promoter progressively increased. The biological significance of the antagonism of naringenin on the specific XRE is not known; however, we speculate that this could facilitate an additive effect on CYP1B1 suppression. Other dietary compounds may antagonise XRE in the other segments of the CYP1B1 promoter, and the combined suppression effect could be magnified.

On the other hand, Sp1-binding sites have also been identified in the $5^{\prime}$-flanking region of $C Y P 1 B 1^{(27,28)}$. The importance of Sp1 sites is not clear. Sp1 binding may initiate repressor activity ${ }^{(29)}$, while others have shown that the binding may confer enhancer activities ${ }^{(30)}$. We have found that the citrus phytochemical also suppressed CYP1A2 expression (data not shown). Since the promoter region of CYP1A2 contains no Sp1, it is unlikely that Sp1 was a factor in the present study.

Protein kinase $\mathrm{C}^{(31)}$ and tyrosine and serine/threonine kinases $^{(32)}$ are potential signalling pathways mediating XRE transactivation. Nevertheless, the present results did not demonstrate any changes in protein kinase $\mathrm{C}$ in cultures treated with naringenin and/or DMBA (data not shown).

The promotive effect of CYP1B1 on breast carcinogenesis is 2-fold. It may initiate mutation by metabolising PAH into DNAdamaging species. In addition, CYP1B1 introduces an $-\mathrm{OH}$ group to oestrogen at the $\mathrm{C}-4$ position to form $4-\mathrm{OH}$ catechol oestrogen $^{(33)}$. The hydroxylated oestrogen is genotoxic while maintaining the oestrogenic properties of its parent compound $^{(33)}$. A previous study has shown that naringenin and citrus juices are protective against DMBA-induced mammary carcinogenesis in Sprague-Dawley rats ${ }^{(1)}$. The present study suggest that CYP1B1 inhibition could be the underlying mechanism.

CYP1B1 is expressed in the heart, kidney, prostate, ovary and mammary gland ${ }^{(34)}$ and can be a potential target for chemoprevention in the tissues ${ }^{(35)}$. Naringenin, as shown in the present study, can be an agent for chemoprotection. The physiological relevance of naringenin dosage in the present study is not known. Vallejo et al. ${ }^{(36)}$ have shown that consuming $400 \mathrm{ml}$ of a commercial orange juice may produce a plasma $C_{\max }$ of $0.44 \mu \mathrm{M}$-naringenin in adults. The lowest effective dose observed in the present study is still achievable from oral consumption.

In conclusion, the present study illustrated that naringenin inhibited the enzyme activity and repressed CYP1B1 mRNA expression with specific XRE antagonism. These properties might be important in nutraceutical development.

\section{Acknowledgements}

This study was supported by the Chinese University of Hong Kong. C. H. P. performed most of the experimental work; T. Y. W. and Y. W. contributed to the EROD enzyme assay and ERE transfection work, respectively. Y. T., M. N. and T. Y. cloned and constructed the CYP1B1 truncation reporter plasmids. L. K. L. designed, coordinated and oversaw the execution of this project. The authors declare that there are no conflicts of interest with respect to this study.

\section{References}

1. So FV, Guthrie N, Chambers AF, et al. (1996) Inhibition of human breast cancer cell proliferation and delay of mam- 
mary tumorigenesis by flavonoids and citrus juices. Nutr Cancer 26, 167-181.

2. Leonardi T, Vanamala J, Taddeo SS, et al. (2010) Apigenin and naringenin suppress colon carcinogenesis through the aberrant crypt stage in azoxymethane-treated rats. Exp Biol Med (Maywood) 235, 710-717.

3. Miller EG, Peacock JJ, Bourland TC, et al. (2008) Inhibition of oral carcinogenesis by citrus flavonoids. Nutr Cancer 60, 69-74.

4. Ekambaram G, Rajendran P, Magesh V, et al. (2008) Naringenin reduces tumor size and weight lost in $N$-methyl- $N^{\prime}$ nitro- $N$-nitrosoguanidine-induced gastric carcinogenesis in rats. Nutr Res 28, 106-112.

5. IARC (editor) (1983) Polynuclear Aromatic Compounds, Part I, Chemical, Environmental and Experimental Data. Lyon: IARC

6. EPA (1990) Aerometric Information Retrieval System (AIRS), Data for 1985-1990 [EP Agency, editor]. Research Triangle Park, NC: US Environmental Protection Agency.

7. Gonzalez FJ \& Gelboin HV (1994) Role of human cytochromes $\mathrm{P} 450$ in the metabolic activation of chemical carcinogens and toxins. Drug Metab Rev 26, 165-183.

8. Dertinger SD, Lantum HB, Silverstone AE, et al. (2000) Effect of $3^{\prime}$-methoxy-4'-nitroflavone on benzo[ $\left.a\right]$ pyrene toxicity. Aryl hydrocarbon receptor-dependent and -independent mechanisms. Biochem Pharmacol 60, 189-196.

9. Kronenberg S, Esser C \& Carlberg C (2000) An aryl hydrocarbon receptor conformation acts as the functional core of nuclear dioxin signaling. Nucleic Acids Res 28, 2286-2291.

10. Safe S (2001) Molecular biology of the Ah receptor and its role in carcinogenesis. Toxicol Lett 120, 1-7.

11. Shimizu Y, Nakatsuru Y, Ichinose M, et al. (2000) Benzo[a]pyrene carcinogenicity is lost in mice lacking the aryl hydrocarbon receptor. Proc Natl Acad Sci U S A 97, 779-782.

12. Buters JT, Sakai S, Richter T, et al. (1999) Cytochrome P450 CYP1B1 determines susceptibility to 7,12-dimethylben$\mathrm{z}[a]$ anthracene-induced lymphomas. Proc Natl Acad Sci US A 96, 1977-1982

13. Zheng W, Xie DW, Jin F, et al. (2000) Genetic polymorphism of cytochrome P450-1B1 and risk of breast cancer. Cancer Epidemiol Biomarkers Prev 9, 147-150.

14. Helmig S, Seelinger JU, Dohrel J, et al. (2011) RNA expressions of $A H R, A R N T$ and $C Y P 1 B 1$ are influenced by AHR Arg554Lys polymorphism. Mol Genet Metab 104, 180-184.

15. Paracchini V, Raimondi S, Gram IT, et al. (2007) Meta- and pooled analyses of the cytochrome P-450 1B1 Val432Leu polymorphism and breast cancer: a HuGE-GSEC review. Am J Epidemiol 165, 115-125.

16. Economopoulos KP \& Sergentanis TN (2010) Three polymorphisms in cytochrome P450 1B1 (CYP1B1) gene and breast cancer risk: a meta-analysis. Breast Cancer Res Treat 122, 545-551.

17. Phillips DH (1999) Polycyclic aromatic hydrocarbons in the diet. Mutat Res 443, 139-147.

18. Tsuchiya Y, Nakajima M \& Yokoi T (2003) Critical enhancer region to which AhR/ARNT and Sp1 bind in the human CYP1B1 gene. J Biochem 133, 583-592.

19. Tsuchiya Y, Nakajima M, Kyo S, et al. (2004) Human CYP1B1 is regulated by estradiol via estrogen receptor. Cancer Res 64, 3119-3125.
20. Bovee TF, Schoonen WG, Hamers AR, et al. (2008) Screening of synthetic and plant-derived compounds for (anti)estrogenic and (anti)androgenic activities. Anal Bioanal Chem 390, 1111-1119.

21. Wang HK, Yeh CH, Iwamoto T, et al. (2012) Dietary flavonoid naringenin induces regulatory $\mathrm{T}$ cells via an aryl hydrocarbon receptor mediated pathway. I Agric Food Chem $\mathbf{6 0}$, 2171-2178.

22. Ciolino HP \& Yeh GC (1999) The flavonoid galangin is an inhibitor of CYP1A1 activity and an agonist/antagonist of the aryl hydrocarbon receptor. Br J Cancer 79, 1340-1346.

23. Livak KJ \& Schmittgen TD (2001) Analysis of relative gene expression data using real-time quantitative PCR and the 2(-Delta Delta C(T)) method. Methods 25, 402-408.

24. Chan HY, Wang H \& Leung LK (2003) The red clover (Trifolium pratense) isoflavone biochanin A modulates the biotransformation pathways of 7,12-dimethylbenz $[a$ ]anthracene. Br J Nutr 90, 87-92.

25. Doostdar H, Burke MD \& Mayer RT (2000) Bioflavonoids: selective substrates and inhibitors for cytochrome P450 CYP1A and CYP1B1. Toxicology 144, 31-38.

26. Hughes D, Guttenplan JB, Marcus CB, et al. (2008) Heat shock protein 90 inhibitors suppress aryl hydrocarbon receptor-mediated activation of CYP1A1 and CYP1B1 transcription and DNA adduct formation. Cancer Prev Res (Phila) 1, 485-493.

27. Tang YM, Wo YY, Stewart J, et al. (1996) Isolation and characterization of the human cytochrome P450 CYP1B1 gene. J Biol Chem 271, 28324-28330.

28. Sun YV, Boverhof DR, Burgoon LD, et al. (2004) Comparative analysis of dioxin response elements in human, mouse and rat genomic sequences. Nucleic Acids Res 32, $4512-4523$

29. Kaczynski JA, Conley AA, Fernandez Zapico M, et al. (2002) Functional analysis of basic transcription element (BTE) binding protein (BTEB) 3 and BTEB4, a novel Sp1-like protein, reveals a subfamily of transcriptional repressors for the BTE site of the cytochrome P4501A1 gene promoter Biochem J 366, 873-882.

30. Wo YY, Stewart J \& Greenlee WF (1997) Functional analysis of the promoter for the human CYP1B1 gene. J Biol Chem 272, 26702-26707.

31. Delescluse C, Lemaire G, de Sousa G, et al. (2000) Is CYP1A1 induction always related to AHR signaling pathway? Toxicology 153, 73-82.

32. Kikuchi H, Hossain A, Yoshida H, et al. (1998) Induction of cytochrome P-450 1A1 by omeprazole in human HepG2 cells is protein tyrosine kinase-dependent and is not inhibited by alpha-naphthoflavone. Arch Biochem Biophys 358, 351-358.

33. Liehr JG (2000) Is estradiol a genotoxic mutagenic carcinogen? Endocr Rev 21, 40-54

34. Shimada T, Hayes CL, Yamazaki H, et al. (1996) Activation of chemically diverse procarcinogens by human cytochrome P-450 1B1. Cancer Res 56, 2979-2984.

35. Peter Guengerich F, Chun YJ, Kim D, et al. (2003) Cytochrome P450 1B1: a target for inhibition in anticarcinogenesis strategies. Mutat Res 523-524, 173-182.

36. Vallejo F, Larrosa M, Escudero E, et al. (2010) Concentration and solubility of flavanones in orange beverages affect their bioavailability in humans. J Agric Food Chem 58, 6516-6524. 